\title{
Diagnostik von Pilzinfektionen der Lunge
}

\author{
Diagnostics for Fungal Infections of the Lungs
}

Autoren

Institute
J. Rupp ${ }^{1,2}$, E. Kramme ${ }^{2}$, H. Schultz ${ }^{3}$, B. Schaaf ${ }^{1,4}$

Medizinische Klinik III, Universitätsklinikum Schleswig-Holstein/Campus Lübeck, Universität zu Lübeck

Institut für Medizinische Mikrobiologie und Hygiene, Universitätsklinikum Schleswig-Holstein/Campus Lübeck

Klinische und Experimentelle Pathologie, Forschungszentrum Borstel

${ }^{4}$ Medizinische Klinik Nord, Klinikum Dortmund

\section{Bibliografie}

DOI http://dx.doi.org/

10.1055/s-0029-1244004

Pneumologie 2010; 64:

300-310 ๔ Georg Thieme

Verlag KG Stuttgart · New York

ISSN 0934-8387

Korrespondenzadresse

PD Dr. med. Bernhard Schaaf

Klinikum Dortmund gGmbH

Münsterstraße 240

44145 Dortmund

bernhard.schaaf@klinikumdo.de

Serienherausgeber

B. Schaaf, Dortmund

G. Rohde, Maastricht

\section{Zusammenfassung}

$\nabla$

Die Erkennung und Therapie von Pilzinfektionen der Lunge stellt auch erfahrene Kliniker immer wieder vor Probleme. Die Abgrenzung invasiver Mykosen der Lunge von nicht therapiebedürftiger Pilzbesiedlung ist klinisch schwierig und kann häufig auch durch weitergehende mikrobiologische Diagnostik nicht hinreichend geklärt werden. Zu unterscheiden sind primäre, häufig lokal begrenzte, endemisch vorkommende pulmonale Mykosen von pulmonalen Mykosen auf dem Boden eines lokal oder systemisch geschwächten Immunsystems. Zu den Risikopatienten zählen dabei insbesondere Personen mit fortgeschrittener HIV-Infektion, Langzeit-Antibiotika-therapierte Patienten sowie onkologische und multimorbide Patienten. Die pulmonale Manifestation einer Mykose kann Ausgangspunkt sein für eine systemische Disseminierung, aber auch im Rahmen einer hämatogenen Streuung auftreten. Letzteres z.B. als invasive pulmonale Aspergillose bei Immunsupprimierten. Die frühzeitige klinische, radiologische und mikrobiologische Diagnosesicherung ist somit essenziell zur Vermeidung von Komplikationen bei pulmonalen Mykosen.

\section{Einleitung}

Auf der Haut und den Schleimhäuten des Menschen gehören Pilze zur Normalflora und schützen den Organismus vor dem Überwuchern potenziell pathogener Erreger. Insbesondere Sprosspilze der Gattung Candida können häufig als Kommensale der menschlichen Flora aus respiratorischen Materialien der unteren Atemwege von Gesunden, insbesondere aber auch von Antibiotika-behandelten Patienten, isoliert werden. Auch ubiquitär in der Umwelt vorkommende, meist aerogen übertragene Pilzsporen von Schimmelpilzen (z.B. Aspergillen und Zygomyceten) können

\section{Abstract \\ $\nabla$}

Recognition of and therapy for fungal infections of the lungs still presents problems even for the experienced clinician. The distinction between invasive mycoses of the lungs and fungal colonisations that do not require therapy is cinically difficult and can often not be made satisfactorily even with advanced microbiological diagnostics. One must differentiate between a primary, often locally limited, endemic pulmonary mycosis and a pulmonary mycosis against the background of a locally or systemically compromised immune system. Patients at risk include those with advanced HIV infections, patients under long-term antibiotic therapy as well as oncological and multimorbid patients. The pulmonary manifestation of a mycosis may not only be the starting point for a systemic dissemination but can also arise in the course of hematogenous spread of the infection. The latter can appear, for example, as an invasive pulmonary aspergillosis in immunesuppressed patients. Thus, early clinical, radiological and biological confirmation of the diagnosis is essential in order to avoid the possible complications of pulmonary mycosis.

als Besiedler ohne Krankheitswert nachgewiesen werden. Humanpathogene Pneumocysten stellen für immungesunde Personen kein Infektionsrisiko dar und werden selten ohne klinisches Korrelat nachgewiesen. Pulmonale Infektionen mit Candida, Aspergillus und den seltenen Zygomyceten treten typischerweise bei Immunsupprimierten als Folge einer hämatogenen Streuung auf. Im Gegensatz zu den genannten Erregern können endemisch vorkommende, meist dimorphe Pilze der Gattungen Blastomyces, Histoplasma und Coccidioides auch bei Personen mit intaktem Immunsystem zu schweren lokalen und generalisierten Mykosen führen. Ein unbestimmter Anteil der 
Infektionen verläuft dabei zunächst subklinisch und kann nach Jahren zu Reaktivierungen, insbesondere unter Immunsuppression, führen.

Die Lunge nimmt bei Pilzinfektionen in zweierlei Hinsicht eine Sonderstellung ein. Zum einen stellt sie funktionell eine Eintrittspforte für Luft-getragene Pilze dar, zum anderen bestimmt sie entscheidend den klinischen Verlauf von Patienten mit systemischen, hämatogen in die Lunge gestreuten Pilzinfektionen.

Allen invasiven Pilzinfektionen gemeinsam ist die im Vergleich zu bakteriellen Infektionen deutlich erhöhte Mortalität, insbesondere bei immungeschwächten Patienten. Neben einem eingeschränkten Repertoire an geeigneten Therapeutika liegt dies insbesondere an den vielfach unzureichenden diagnostischen Möglichkeiten zum Nachweis invasiver Pilzinfektionen in der Abgrenzung zur Kontamination und einer kommensalischen Besiedlung. In diesem Übersichtsartikel werden zentrale Charakteristika, Möglichkeiten und Limitierungen der derzeit verfügbaren Diagnostik endemischer als auch opportunistischer Mykosen mit Befall der Lunge herausgestellt.

\section{Endemische pulmonale Mykosen}

Ein Großteil der für den Menschen gefährlichen Pilze, die endemische Systemmykosen verursachen können, gehören den dimorphen Pilzen an. Sie werden vermehrt im Erdreich und organischen Abfällen gefunden und können in Abhängigkeit von der Umgebungstemperatur und vorhandener Nährstoffquellen zwischen filamentösem Wachstum (Schimmelpilze) und einem Sprosszell-Stadium wechseln. In Tab. 1 ist die geografische Verbreitung der drei häufigsten endemischen Pilzinfektionen, für die pulmonale Manifestationen beschrieben sind, zusammengefasst: Blastomykose, Histoplasmose und Coccidiomykose.

Klinisch manifeste Infektionen der Lunge mit endemischen Pilzen gehen in über 50\% der Fälle mit Allgemeinsymptomen wie Fieber, Schüttelfrost, produktivem Husten, Myalgien, Arthralgien und pleuritischen Schmerzen einher. Dabei kann die Infektion lediglich die Lunge betreffen oder im Rahmen von systemischen Erkrankungen auftreten. Inapparente Verläufe kommen bei allen Erregern vor. Bei Patienten mit Immunsuppression verläuft die Infektion typischerweise schwerer und häufiger disseminiert, zudem kann es auch nach Jahren zu einer Reaktivierung bei latenter Infektion kommen [1,2].

\section{Opportunistische Mykosen bei Immunsuppression}

Neben endemischen Mykosen treten pulmonale Pilzinfektionen fast ausschließlich als opportunistische Infektion bei Patienten mit Immunsuppression auf. Die klinisch bedeutsamsten sind Infektionen mit Aspergillus sp., Candida sp., Pneumocystis jiroveci, Zygomyceten und Cryptococcus neoformans. Verminderte Anzahl oder Funktionsstörungen von neutrophilen Granulozyten sind mit einer Häufung von Pilzinfektionen assoziiert. Hierzu zählt die anhaltende Neutropenie nach Chemotherapien (länger als 10 Tage), die Organ- und Knochenmarktransplantation, die immunsuppressive Therapie bei Systemerkrankung, die fortge-

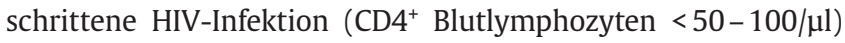
und die prolongierte systemische Glukokortikoidtherapie (Risikofaktoren siehe $\bullet$ Tab. 2).

Die Erkrankung erfolgt zumeist auf dem Boden eines Ungleichgewichts zwischen menschlichem Immunsystem (inkl. schützen-
Tab. 1 Geografische Verteilung endemischer Mykosen.

\begin{tabular}{|l|l|}
\hline Spezies & $\begin{array}{l}\text { Endemiegebiete } \\
\text { Blastomyces dermatitides } \\
\text { Kanada, Süd-zentrale/-östliche Regionen } \\
\text { und der mittlere Westen der USA } \\
\text { vereinzelte Herde in Zentral- und } \\
\text { Südamerika, in Teilen Afrikas }\end{array}$ \\
\hline Histoplasma capsulatum & $\begin{array}{l}\text { Südwesten der USA, Ohio und Mississippi, } \\
\text { Mexiko, Afrika, Südostasien, Indien }\end{array}$ \\
\hline Coccidioides immitis & $\begin{array}{l}\text { Südwesten der USA (Flussdelta von Ohio, } \\
\text { Missouri und Mississippi), Mexiko, Süd- } \\
\text { amerika }\end{array}$ \\
\hline Quelle: www.cdc.gov/ncidod/dbmd/diseaseinfo/
\end{tabular}

Tab. 2 Risikofaktoren für invasive Pilzinfektionen.

Risikofaktoren
Neutropenie $(<500 / \mu \mathrm{l}) \geq 10$ Tage
Immunsuppression in den letzten 30 Tagen
Antibiotika refraktäres Fieber $>96$ Stunden
Temp. $>38^{\circ} \mathrm{C}$ oder $<36^{\circ} \mathrm{C}$ bei Z. $\mathrm{n}$. prolongierter Neutropenie in den
letzten 60 Tagen
Z.n. gesicherter/wahrscheinlicher invasiver Pilzinfektion während
Neutropenie
symptomatisches AIDS
„graft versus host disease“
$>3$ Wochen Kortikosteroidtherapie innerhalb der letzten 30 Tage

der Normalflora) und dem Überwuchern fakultativ pathogener Pilzarten. Der Besiedlung des oberen Nasenrachenraums mit opportunistischen Pilzen wie Aspergillus sp. oder Candida sp. erhöht bei Risikopatienten die Wahrscheinlichkeit, an einer invasiven Mykose zu erkranken. Eine Sonderstellung hat die Pneumocystis jiroveci-Pneumonie (PcP), die durch die AIDS-Epidemie in den 80er-Jahren eine rasante Zunahme erfahren hat. Heutzutage wird die PcP insbesondere bei Patienten mit hämatologischen Erkrankungen, Systemerkrankungen und nach Transplantationen vermehrt beobachtet.

\section{Diagnostik der pulmonalen Pilzinfektion $\nabla$}

Die Diagnose einer pulmonalen Mykose wird in der Zusammenschau der klinischen, radiologischen, mikrobiologischen und histopathologischen Befunde gestellt.

\section{Klinisches Bild}

Das klinische Bild entspricht bei lokalen pulmonalen Prozessen einer Pneumonie, bei generalisierten Prozessen findet sich eine systemische Infektion mit Beteiligung verschiedener Organsysteme. Die Symptomatik reicht daher von unspezifischen Symptomen des Allgemeinbefindens, über pulmonale Symptome bis hin zu Symptomen der Multiorganbeteiligung (z. B. Zeichen der Sepsis, des Nierenversagens, der Enzephalitis).

\section{Radiologie}

Das radiologische Bild pulmonaler Mykosen reicht von fokalen Prozessen, über multiple Abszesse bis hin zur miliaren Aussaat. Als sensitivere und aussagekräftigere Alternative zur Standardröntgenaufnahme kommt das High-Resolution- oder Multi-SliceCT, häufig mit charakteristischem Bandenmuster, zur Anwendung [3]. 


\section{Bronchoskopie}

Neben der Basisdiagnostik von Sputum, Blutkultur und Punktionsmaterial bei pleuralem Erguss (Sensitivität ca $25 \%$ bei Candida- oder Aspergilluspneumonie) wird die Bronchoskopie mit bronchoalveolärer Lavage (BAL) zur gezielten Materialgewinnung eingesetzt. Aufgrund des relativ geringen Komplikationsrisikos sollte die Indikation großzügig gestellt werden. Bei beatmeten Patienten kann auch Tracheobronchialsekret untersucht werden. Asservierte Blutkoagel eignen sich ebenfalls zur mikrobiologischen und histologischen Untersuchung auf Pilze. Aufgrund des erhöhten Komplikationsrisikos (Blutungen, Pneumothorax) sollten Gewebsentnahmen nur durchgeführt werden, wenn ein wegweisendes Resultat erwartet werden kann. Die Trefferquote der transbronchialen Biopsie (TBB) ist besser bei diffusen Prozessen, schlechter bei einzelnen Noduli [4]. Die CT- oder Ultraschall-gesteuerte transthorakale Feinnadelbiopsie (FNAB) bietet sich alternativ bei pleuranahen fokalen Infiltraten an [5]. Die höchste Aussagekraft erhält man mit der Kombination aus videoassistierter Thorakoskopie (VATS) und offener Lungenbiopsie (OLB), jedoch auch mit einer deutlichen Zunahme schwerer Komplikationen (ca. 5\%) [6].

\section{Mikrobiologische Befunde}

Die kulturelle Anzucht aus respiratorischem Material (Sputum, Trachealsekret, BAL, Pleuraerguss), Blutkultur oder Gewebe ist der Goldstandard des Pilznachweises (s. $\odot$ Tab. 4). Der Verdacht auf eine Pilzinfektion der Lunge sollte im Vorfeld dem untersuchenden Labor mitgeteilt werden, damit durch längere Inkubationszeiten auch langsam wachsende Pilze erfasst werden können. Gewebe sollte in physiologischer Kochsalzlösung und nicht in Formalin verbracht werden. Mithilfe molekulargenetischer Verfahren lassen sich humanpathogene Candida sp., Aspergillus sp. und Cryptococcus sp. im Nativmaterial von respiratorischen Sekreten und Gewebebiopsien nachweisen. Bei unbekanntem Erreger können konservierte Genomabschnitte mittels spezifischer Primer in der PCR amplifiziert und mittels Sequenzierung zur Identifizierung herangezogen werden. Die Austestung von Resistenzmustern klinisch-relevanter Pilzisolate ist bislang allein für Candida sp. hinreichend etabliert. Derzeit verfügbare serologische Verfahren zum Nachweis von Antigenbestandteilen oder Antikörpern gegenüber einzelnen Pilzspezies sind zumeist wenig spezifisch und sollten bei klinischem Verdacht allenfalls zur Verlaufskontrolle einer invasiven Mykose genutzt werden.

\section{Histopathologische Befunde}

Der histopathologische Nachweis des invasiven Wachstums von Pilzen im Gewebe ist beweisend für die Diagnosestellung. Bei endemischen Infektionen finden sich gehäuft Granulome. In einigen Fällen, insbesondere nach Vortherapie, lassen sich Pilze lediglich histologisch und nicht kulturell nachweisen. In Einzelfällen können auch molekulargenetische Untersuchungen auf Pilze aus dem Gewebe durchgeführt werden. Wie für die Kultur, sollte auch für den Nukleinsäurenachweis aus dem Gewebe das Material in $\mathrm{NaCl}$ eingesandt werden. Der Nukleinsäurenachweis aus Formalinproben ist prinzipiell möglich, die Sensitivität jedoch deutlich erniedrigt.

\section{Die Erreger im Einzelnen}

$\nabla$

\section{Endemische pulmonale Mykosen \\ Blastomykose}

Epidemiologie: In Endemiegebieten ( $\bullet$ Tab. 1) von Blastomyces dermatitidis treten 1-2 Erkrankungsfälle pro 100000 Einwohner im Jahr auf. Die Infektion erfolgt über die Inhalation von Luft-getragenen Konidien (Sporen). Besonders häufig betroffen sind Landwirte, Forstarbeiter und Rucksacktouristen. Epidemiologische Untersuchungen in Wisconsin haben gezeigt, dass warmes und feuchtes Erdreich eine wichtige Infektionsquelle darstellt [7]. In funktionellen Assays zur Lymphozytenproliferation konnte nachgewiesen werden, dass asymptomatische oder subklinische Verläufe bei exponierten Personen häufig sind [8].

Klinik: Die Blastomykose ist eine systemische Erkrankung mit einer Vielzahl pulmonaler und extrapulmonaler Manifestationen. Bei etwa $3 / 4$ der Patienten wird bei Diagnosestellung ein isolierter Lungenbefall vorgefunden. Nahezu alle Patienten mit extrapulmonalem Befall (am häufigsten Haut) haben eine aktive pulmonale Infektion [9]. Die akute pulmonale Infektion (Inkubationszeit: 30-45 Tage) verläuft zu 50\% asymptomatisch und wird meist mit viralen oder bakteriellen Infektionen verwechselt [7]. Insbesondere Patienten mit Lungenversagen haben eine hohe Mortalität (> 50\%) [10]. Chronische Verläufe bei nicht ausgeheilter symptomatischer oder initial asymptomatischer Pneumonie kommen vor, obgleich eine Reaktivierung, wie sie bei der Tuberkulose gefunden wird, bislang nicht bewiesen ist $[1,11]$.

Bildgebung: Der radiologische Befund zeigt meist eine auf ein Lungensegment oder einen Lungenlappen begrenzte Pneumonie ohne Lymphadenopathie. Patienten mit chronischer Blastomykose zeigen Konsilidierungen, die Malignome vortäuschen können. Miliare, fibro-zirrhotische und abszedierende Formen kommen vor. Die Differenzialdiagnose umfasst bakterielle Pneumonien, Mykobakteriosen, andere Pilzinfektionen und pulmonale Neoplasien.

Mikrobiologie: Bei symptomatischen Infektionen der Lunge mit $B$. dermatitidis findet sich zumeist ein purulenter, zellreicher Auswurf, aus dem sich kulturell die Erreger nachweisen lassen. Mit der Bronchoskopie lässt sich unter Verwendung spezieller Pilzfärbungen (z.B. nach Gomori oder PAS [Perjodsäure-SchiffReaktion]-Färbung) [12] in 2/3 der Fälle eine pulmonale Blastomykose bereits zytologisch nachweisen [13]. Aufgrund morphologischer Merkmale und des Wachstumsverhaltens bei 25 und $37^{\circ} \mathrm{C}$ lässt sich $B$. dermatitidis relativ einfach von anderen dimorphen Pilzen abgrenzen. Als Direktnachweis können Antigen-Fluoreszenzteste und Hybridisierungstechniken (u.a. FISH) eingesetzt werden, für die bislang jedoch keine größeren Studien zur Sensitivität vorliegen.

Histopathologie: Die initiale pulmonale Gewebsreaktion auf Blastomyceten ist ein granulozytäres Zellinfiltrat, gefolgt von einer histiozytären und granulomatösen Entzündung (nicht verkäsende Granulome) [14,15]. In Hautbiopsaten finden sich Mikroabszesse (Pyogranulome). Die Granulome sind typischerweise aufgebaut aus einem Zentrum nekrotischer Granulozyten, umrandet von einem Epitheloidzellsaum. Pilze werden innerhalb des purulenten Zentrums und innerhalb von Histiozyten gefunden. Sie sind rund, relativ uniform mit einer Größe von 8 bis $15 \mu \mathrm{m}$ und weisen eine dicke, doppelbrechende Wand um das Protoplasma auf. In der Histologie können die Erreger in der Silber- oder der PAS-Färbung dargestellt werden. Eine klare morphologische Abgrenzung zu C. neoformans kann mitunter schwierig sein. 


\section{Histoplasmose}

Epidemiologie: Die höchste Inzidenz für eine Infektion mit $H$. capsulatum findet sich in Ohio und am Mississippi. Der dimorphe Keim (Gruppe der Askomyceten) kommt in feuchter (67-87\%), warmer Erde $\left(22-29^{\circ} \mathrm{C}\right)$ und mit Vogel- bzw. Fledermauskot vermischter Erde vor. Infektionsgefährdet sind daher Fledermausund Höhlenforscher, Obdachlose, Stall-, Dach- und Brückenarbeiter.

Klinik: Die primäre Infektion durch Inhalation von Myzelfragmenten oder Mikrokonidien ist zu $>90 \%$ asymptomatisch oder selbst limitierend (80\% der Bevölkerung in Endemiegebieten ist im Hauttest positiv), kann aber bei Kleinkindern ( $<2 \mathrm{~J}$.), älteren und immunsupprimierten Patienten lebensgefährliche Infektionen verursachen. Nach einer Inkubationszeit von durchschnittlich 14 Tagen kommt es typischerweise zu septischen Temperaturen (bis $42^{\circ} \mathrm{C}$ ), Kopfschmerz, Husten und Thoraxschmerzen, in einigen Fällen verbunden mit Arthralgien, Erythema nodosum und Erythema multiforme. Eine ausführliche Übersicht findet sich bei Sudeck [16].

Bildgebung: Radiologisch findet sich bei der akuten Form eine flächige Pneumonitis (zum Teil mit Verkalkungen), verbunden mit einer hilären Lymphadenopathie. In 10-25\% der Histoplasmose-infizierten HIV-Patienten entwickelt sich eine disseminierte Histoplasmose mit akuter Sepsis, Meningitis und Befall von Leber und Milz. Für die chronische Verlaufsform (typisch bei $>$ 50-jährigen Männern mit chron. Lungenerkrankung) sind meist Oberlappen-betonte, seltener hilusnahe, retikuläre, grobknotige, fibrotische oder kavernöse, klinisch nicht von der Tuberkulose zu unterscheidende Infiltrate typisch. Differenzialdiagnostisch müssen neben der Tuberkulose die atypischen Mykobakteriosen, die Melioidose, die Sarkoidose und Tumoren bedacht werden. Raritäten sind das mediastinale Granulom, die fibrosierende Mediastinitis und die Broncholithiasis.

Mikrobiologie: Der kulturelle Nachweis von $H$. capsulatum gelingt am besten bei $25^{\circ} \mathrm{C}$ auf Sabouraud Dextrose Agar und kann bis zu 6 Wochen dauern. Die lichtmikroskopische Differenzierung der Makrokonidien erlaubt zumeist die Identifizierung von Histoplasmen, jedoch wird die Bestätigung durch PCR oder Antigen-basierte Verfahren (DNA-Sonden, Exoantigen-Test) empfohlen. Die Serologie zum Nachweis von spezifischen Antikörpern gegen $H$. capsulatum ist nur bei immunkompetenten Patienten verwertbar. Die Bestimmung von $H$. capsulatum Polysaccharidantigenen hat bei disseminierter Infektion im Urin eine höhere Empfindlichkeit als im Serum [17] (nicht routinemäßig erhältlich). So können in der akuten Phase respiratorischer Histoplasma-Infektionen in bis zu 75\% Antigene im Urin nachgewiesen werden. Allerdings erschweren falsch positive Antigenbefunde bei Immunsupprimierten die Diagnostik. Kreuzreaktivitäten mit Blastomyces sp., Penicillium sp. oder Aspergillus sp. sind beschrieben [18]. Der früher eingesetzte Hauttest zum Nachweis einer Exposition mit Histoplasmen wird aufgrund unzureichender Spezifität heutzutage nur noch in der akuten Ausbruchssitutation verwendet.

Histopathologie: Der Nachweis von $2-4 \mu \mathrm{m}$ großen, ovalen, schmalbasig knospenden Pilzen im Gewebe ist hinweisend für eine Infektion mit Histoplasmen. Die beste Darstellung von $H$. capsulatum im Gewebe wird mit der Methenamin-Silberfärbung oder PAS-Färbung erzielt. Die akute pulmonale Histoplasmose erzeugt einen nekrotisierenden, granulomatösen Entzündungsprozess, wobei der zentrale Anteil der Granulome oft aus multiplen konzentrischen Lamellen aufgebaut ist, die makroskopisch an Wachstumsringe eines Baumstammes erinnern. Die gut um- schriebenen Granulome zeigen zentral geschichtetes azelluläres Kollagen, häufig vergesellschaftet mit Verkalkungen. Zahlreiche Organismen können in der zentralen Nekrosezone nachgewiesen werden. Im Gegensatz hierzu zeigt die disseminierte Histoplasmose bei geschwächter immunologischer Abwehr keine Bildung von Granulomen und die Erreger sind in Makrophagen innerhalb verbreiterter Alveolarsepten und in Alveolarräumen zu erkennen [19-21]. In Lungenbiopsien werden häufig erst bei massivem Befall Histoplasmen im Gewebe sichtbar, bei der granulomatösen Mediastinitis können im Einzelfall nekrotische Lymphknoten für die Diagnostik herangezogen werden.

\section{Coccidioidomykose}

Epidemiologie: Coccidioides spp. (C. immitis und C. posadasii) sind dimorphe Pilze und kommen lediglich in niedrig gelegenen Wüsten mit heißem, trockenem Wetter vor. Zu Infektionen kommt es in Kalifornien gehäuft in den Sommermonaten, nachdem die Erde von den Winterregen getrocknet ist. In Arizona hat man in den Jahren 1990 - 1995 einen deutlichen Anstieg der Infektionen mit Coccidioides immitis verzeichnet mit einer Prävalenz von bis zu 15 auf 100000 Einwohner [22]. Größere Ausbrüche in diesen Regionen finden sich zumeist nach Naturkatastrophen (insbesondere Sandstürme, Erdbeben), bei denen hohe Mengen infektiöser Arthroconidien in die Umgebung freigesetzt werden. In Endemiegebieten sind $15-50 \%$ der Bevölkerung bereits schon einmal mit dem Erreger in Kontakt gekommen. Sogenannte Sphärulen mit einem Durchmesser von 30-60 $\mu \mathrm{m}$ bilden das Reservoir für infektiöse Endosporen, die bei immunsupprimierten Patienten systemisch disseminieren können. So ist die Übertragung von Coccidioides im Rahmen von Lungentransplantationen bei Spendern aus Endemiegebieten beschrieben [23].

Klinik: Infektionen nach Inhalation der Arthroconidien verlaufen meist asymptomatisch oder subakut mit leichten respiratorischen Symptomen, die nicht diagnostisch wegweisend sind. Auch leichte Primärinfektionen können im Verlauf (bis zu 2 Jahre) zu pulmonalen Komplikationen führen. Typisch für die akute Infektion ist ein fein-papulärer Hautausschlag, verbunden mit einem Erythema nodosum oder E. multiforme und Fieber (sog. „Wüstenrheuma“). Laborchemisch fallen ein erhöhte BSG sowie eine ausgeprägte Eosinophilie auf.

Bildgebung: Radiologisch finden sich typischerweise einseitige Infiltrate mit Pleuraerguss und hilärer Lymphadenopathie. Gefürchtet sind Spontanpneumothoraces nach der Ruptur dünnwandiger Kavernen. Asymptomatische, bis zu $5 \mathrm{~cm}$ große Knoten können mit einer Neoplasie verwechselt werden. Ein disseminierter Lungenbefall zum Teil mit fulminantem klinischem Bild ähnlich einem septischen Schock ist bei Patienten mit angeborener oder erworbener Immunsuppression (HIV-Patienten mit CD4-Zellen $<100 / \mu \mathrm{l})$, schwangeren Frauen und Schwarzafrikanern beschrieben $[24,25]$. Bei Diabetespatienten und Patienten mit Lungenfibrose (nicht bei HIV-Patienten) kommt eine chronische fibrokavernöse Form mit B-Symptomen, ähnlich der Tuberkulose, vor.

Mikrobiologie: Die Pilzkultur ist der Goldstandard in der Diagnostik. Ergibt sich anhand des Wachstumsverhaltens und mikroskopischer Untersuchungen der begründete V.a. eine Infektion mit Coccidioides sp., sollte, aufgrund der hohen Infektiosität, die weitere Identifizierung in Speziallabors erfolgen. Durch die unzureichende Sensitivität des Direktnachweises von Coccidioides in respiratorischen Sekreten und in histologischen Präparaten haben sich in den vergangenen Jahren zunehmend molekularbiologische Verfahren durchgesetzt. Mithilfe fluoreszenzmar- 
kierter Sonden lassen sich somit die Erreger innerhalb von $4 \mathrm{~h}$ aus respiratorischem Material mit einer Sensitivität von 100\% und einer Spezifität von 98,4\% bestimmen [26]. Der serologische Nachweis eignet sich zur Bestimmung einer durchgemachten Infektion, nicht aber für die Primärdiagnostik, und wird meist 1-2 Wochen nach Erregerexposition positiv.

Histopathologie: In Lungenbiopsien lassen sich charakteristische Ansammlungen von $C$. immites meist schon in der HämatoxylinEosin-Färbung oder der Gomori-Silberfärbung nachweisen. Eine nekrotisierende granulomatöse Entzündung charakterisiert die Coccidiomykose $[27,28]$. Häufig ist eine eosinophile Pneumonie im angrenzenden Lungenparenchym nachweisbar [29,30]. Sphärulen werden als große runde Strukturen in einer Größe von 30 bis $60 \mu \mathrm{m}$ mit einer dicken, bräunlichen Zellwand sichtbar, die basophile Endosporen enthalten. Mit der Ruptur der Sphärulen werden die Endosporen frei und können dann innerhalb von Nekrosen nachgewiesen werden.

\section{Opportunistische Mykosen bei Immunsuppression}

\section{$\nabla$}

\section{Schimmelpilze}

Aspergillose

Epidemiologie: Aspergillus sp. kommen weltweit in Erde, Wasser und Luft vor und finden sich insbesondere bei vergammelter Vegetation und verdorbenen Speisen. Als Quelle einer exogenen Exposition mit Aspergillen bei hospitalisierten Patienten wurden wiederholt Bauarbeiten bzw. Renovierungsarbeiten in unmittelbarer Nähe von Intensivstationen oder Transplantationseinheiten ausfindig gemacht [31]. Der Mensch infiziert sich über Inhalation mit Aspergillus-Sporen oder direkte Kontamination von chirurgischen Wunden und intravenösen Kathetern. Insbesondere Störungen der neutrophilen Granulozyten durch protrahierte Glukokortikoid-Gaben (z.B. bei COPD) [32] und Chemotherapien sind mit invasiven Aspergillosen assoziiert ( Tab. 2).

Klinik: Klinisch zu unterscheiden ist die Besiedlung von der Erkrankung mit Aspergillen. Das Aspergillom (in vorgeformter Höhle z.B. bei tuberkulöser Kaverne oder Lungenemphysem) und die allergische bronchopulmonale Aspergillose (ABPA) kommen bei immunkompetenten, die invasive pulmonale Aspergillose (IPA), die systemische Aspergillose (hohe Mortalität) und die nekrotisierende Tracheobronchitis bei immunsupprimierten Patienten vor. Bei der IPA wird anhand der Klinik, Bildgebung, Mikrobiologie und Histopathologie zwischen gesicherter, wahrscheinlicher und möglicher Erkrankung unterschieden ( Tab. 3) [33].

Bildgebung: Das Halo-Zeichen (Infiltrat/Konsolidation mit Milchglasrandsaum als frühes Zeichen), das Luftsichelzeichen (spätes Zeichen), Einschmelzungen (cavitärer Lufteinschluss) und keilförmige Infiltrate sind typische Veränderungen in der CT bei Schimmelpilzinfektionen [34]. Radiologisch scheint das Halo-Zeichen am besten geeignet, um CT-morphologisch eine IPA zu diagnostizieren [35].

Mikrobiologie: In über $80 \%$ der kulturell nachgewiesenen Aspergillus-Infektionen finden sich Aspergillus fumigatus und A. flavus, sehr viel seltener werden auch $A$. niger, $A$. nidulans und $A$. terreus gefunden ( $\bullet$ Abb. 1). Der kulturelle Nachweis von Aspergillus sp. hat bei immunkompetenten Patienten ohne radiologischen Nachweis eines Aspergilloms meist keine klinische Relevanz und ist Zeichen einer Kontamination des Untersuchungsmaterials oder einer Besiedlung der Schleimhaut. Der Nachweis von Aspergillus sp. aus Sputum oder BAL-Flüssigkeit bei Hochrisikopatien-
Tab. 3 Diagnostische Kriterien für eine Pilzpneumonie (adaptiert nach [31]).

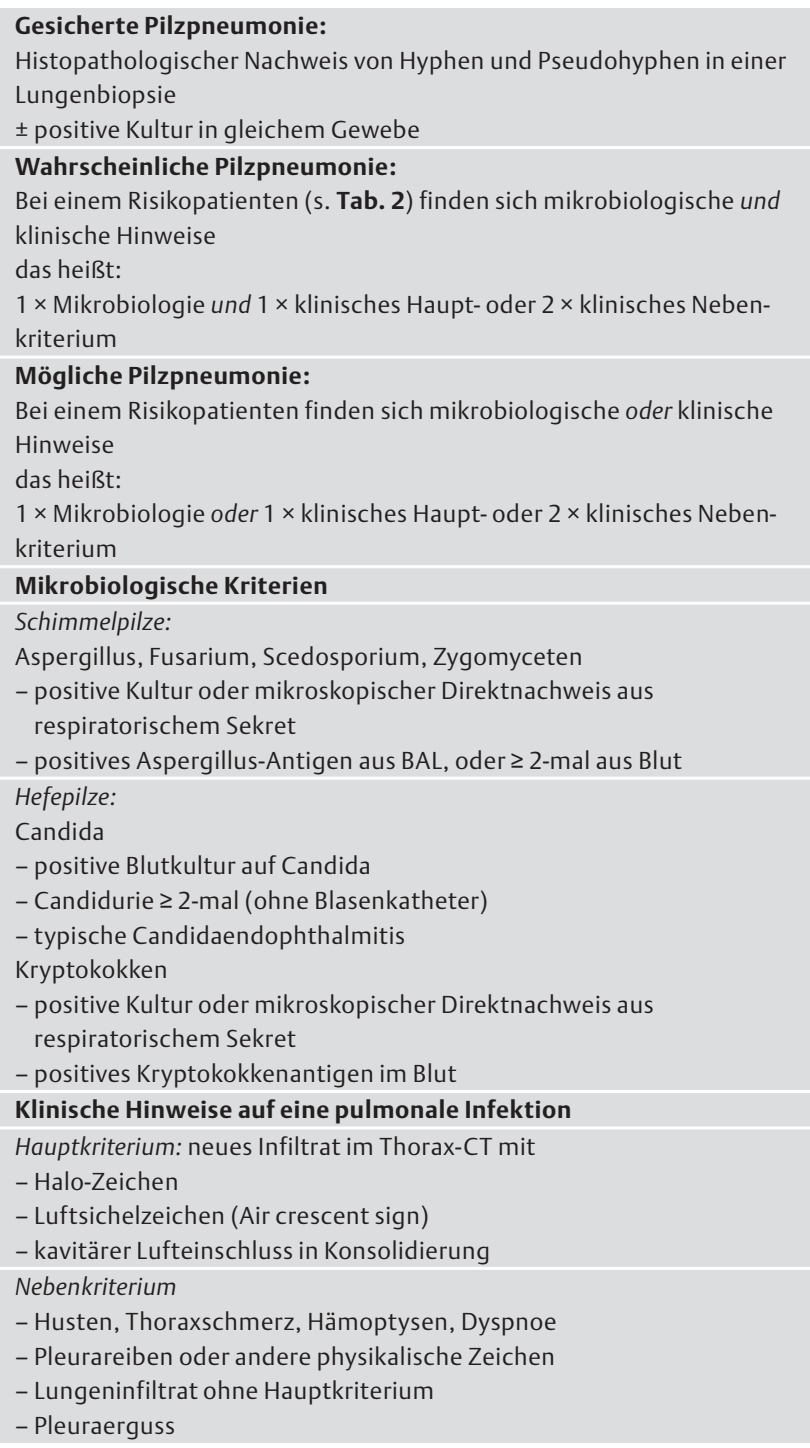

ten hat hingegen einen prädiktiven Wert von 60 -80\% für das Vorliegen einer IPA [36-38]. Als Material für die kulturelle Anzucht sind Lungengewebsbiopsate der BAL oder Absaugungen der tiefen Atemwege deutlich überlegen. Die semiquantitative Bestimmung der Pilzlast aus BAL-Flüssigkeit mittels Kultur kann eventuell zur Verlaufskontrolle herangezogen werden [39].

Als zusätzliches Verfahren hat sich bei hämato-onkologischen Hochrisikopatienten ein Latex-Agglutinationstest zum Nachweis von Galactomannan im Serum etabliert. Für eine Interpretation der Ergebnisse sind Titerverläufe (z.B. wöchentlich) notwendig. Falsch positive Tests kommen bei Einzelpunkt-Messungen, z.B. bei gleichzeitiger bzw. vorangegangener $\beta$-Laktam-Antibiotikatherapie in einem Zeitraum bis zu 5 Tagen nach der letzten Gabe vor [40]. Auch Nicht-Aspergillus sp. wie Blastomyces können zu falsch positiven Ergebnissen führen [41]. Die Testung von Galactomannan aus BAL-Flüssigkeit bei Patienten nach Organtransplantation [42], hämatologischen Risikopatienten [43] und Patienten mit Pneumonie auf Intensivstationen kann zu einer frühzeitigeren Diagnosestellung einer IPA führen [44]. Bei einem Cutoff von 0,5 kommt es jedoch zu vermehrt falsch positiven Befunden, z.B. durch asymptomatische Besiedlung transplantierter Lungen [42]. 


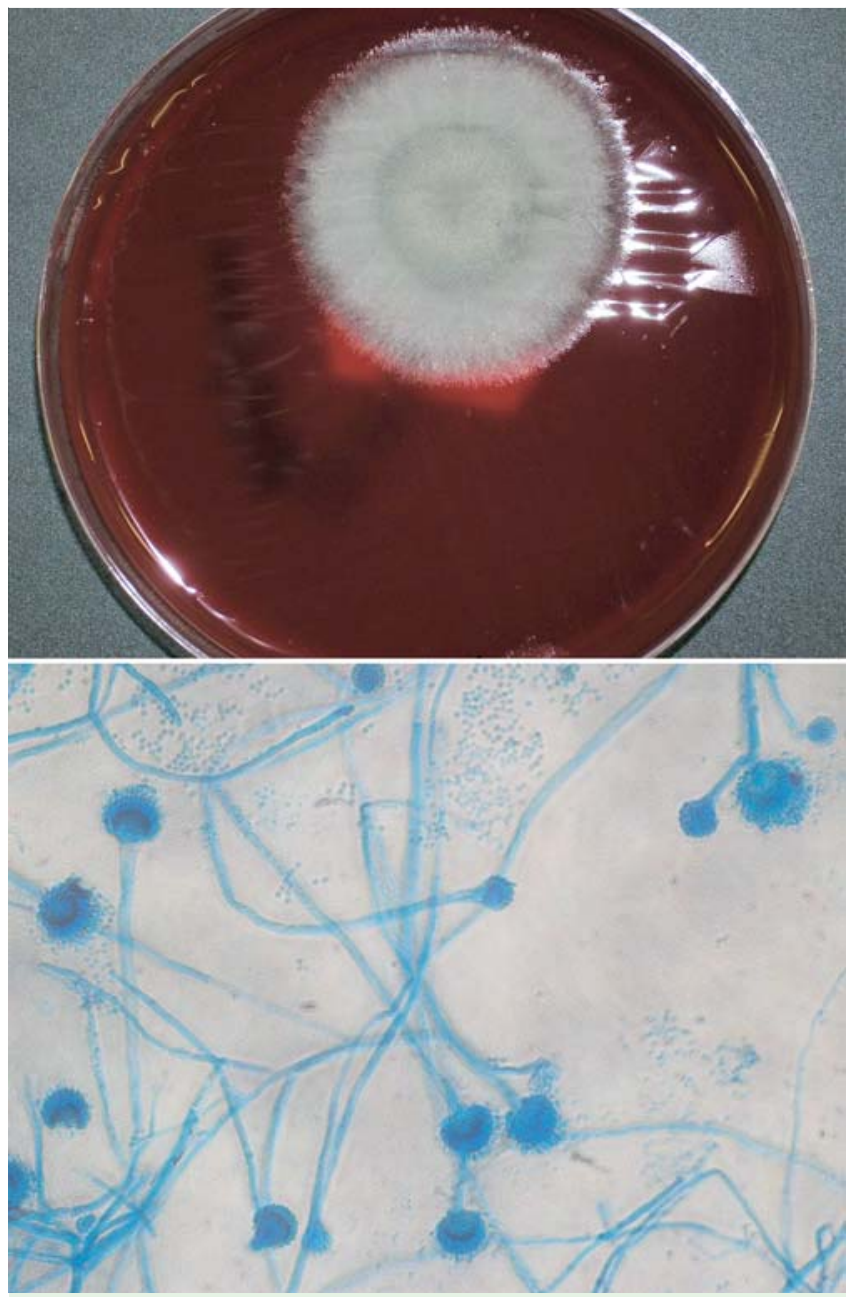

Abb. 1 Kultur und Mikroskopie von Aspergillus fumigatus. Kultureller Nachweis und mikroskopische Erscheinungsform von A. fumigatus. Die Identifizierung erfolgt aufgrund charakteristischer Merkmale in der Anordnung und Morphologie unterschiedlicher Pilzstrukturen.

Der Direktnachweis mittels PCR-Verfahren bei IPA ist aus respiratorischem Material und Gewebe möglich. Ob in BAL die in kleinen Studien gezeigte Sensitivität von ca $75 \%$ und Spezifität von ca. $90 \%$ diagnostische und therapeutische Vorteile erbringt, ist noch nicht abschließend geklärt $[45,46]$. Der in diesen Studien gezeigte negative prädiktive Wert von über 95\% könnte von größerer klinischer Relevanz sein als der positive prädiktive Wert, der aufgrund möglicher Kolonisation des Respirationstraktes mit ca $50 \%$ niedrig ausfällt $[45,46]$.

Histopathologie: Die klassische Gewebsreaktion bei der IPA ist die hämorrhagische Infarzierung mit einem spärlichen, entzündlichen Zellinfiltrat. Die Pilzhyphen infiltrieren Alveolarsepten und Blutgefäße, wobei die arteriellen Gefäße von den Hyphen verschlossen werden können oder sekundär thrombosieren. Aspergillus fumigatus stellt sich als langes, septiertes Myzel mit einem Durchmesser von bis zu $4 \mu \mathrm{m}$ dar und weist typischerweise dichotome Aufzweigungen in einem Winkel von 45 Grad auf. Das Myzel ist charakteristischerweise parallel oder radiär zu einem Zentrum ausgerichtet ( $\bullet$ Abb. 2). Die seltene, nekrotisierende Tracheobronchitis ist charakterisiert durch ausgedehnte Ulcerationen von Trachea und Bronchien mit oberflächlicher Pilzbesiedlung und Bildung von Pseudomembranen [47,48]. Das Aspergillom (nicht invasive, saprophytische Pilzballen, sog. Myzetome) bildet sich in vorbestehenden Hohlräumen (Emphysem-

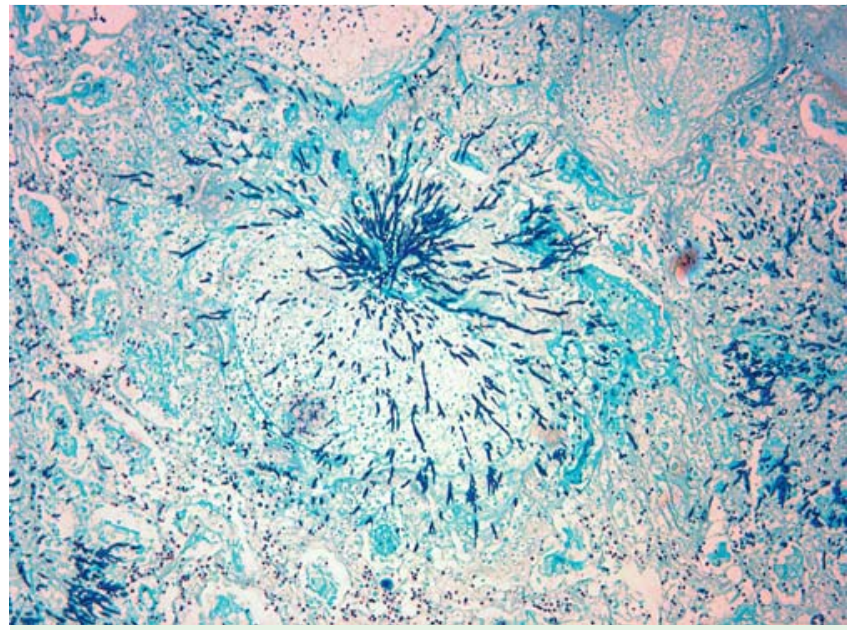

Abb. 2 Invasive Aspergilluspneumonie. Extensive Gewebsinvasion von Aspergillus mit Infarzierung des Lungenparenchyms bei geringer entzündlicher Reaktion. Radiäre Ausbreitung der relativ uniformen Pilzhyphen durch Alveolarsepten und Gefäße. Versilberung nach Grocott $(100 \times$ Vergrößerung).

blasen, Bronchiektasen, Kavernen bei Tuberkulose, Lungeninfarkte) [47-49]. Histologisch zeigt das Aspergillom eine meist geschichtete und lamellenartige Anordnung der Pilzmassen. Bei Aspergillus niger sind Ablagerungen von Calciumoxalatkristallen charakteristisch und können gelegentlich in der Sputumzytologie nachgewiesen werden $[50,51]$.

\section{Zygomykose}

Epidemiologie und Klinik: Systemische und pulmonale Infektionen mit Zygomyzeten (insbesondere Rhizopus sp., Mucor sp. und Absidia sp.) und anderen, seltenen Schimmelpilzen (z. B. Fusarium, Trichosporon und Scedosporium) sind lebensbedrohliche Erkrankungen bei Patienten mit Immunsuppression [52]. Lokale Manifestationen finden sich in den oberen und unteren Atemwegen sowie in der Haut. Die Mortalität bei isoliertem Befall der Lunge als sogenannte „break-trough“-Infektion, z.B. unter Voriconazol, ist hoch (76\%) [53]. Ein Drittel der Patienten hat eine systemische Dissemination mit nahezu 100\% Mortalität [54]. Eine Mitbeteiligung der Nasennebenhöhlen, das Vorliegen eines Diabetes mellitus sowie das Auftreten von Mikroknötchen ( $<1 \mathrm{~cm}$ Größe) und multipler Knötchen (> 10/Lunge) im CT-Thorax sind typische Hinweise für eine pulmonale Zygomykose.

Mikrobiologie: Die Anzucht von Zygomyzeten kann sowohl aus respiratorischen Sekreten ( $\bullet$ Abb.3) als auch Lungenbiopsien versucht werden und ist bei Schädigung des Gewebes jedoch erschwert. Der kulturelle Nachweis korreliert nur in $8 \%$ tatsächlich mit dem klinischen Bild einer invasiven Zygomykose [55]. In der Mikroskopie erfolgt der Nachweis mit 10\% KOH-Lösung oder Calcofluor-weiß-Färbung. Aufgrund häufig langwieriger Kulturbedingungen und der potenziellen Gefahr für „health-care workers“ und Laborpersonal ist die PCR für die Diagnostik von Zygomykosen sinnvoll $[26,52]$.

Histopathologie: Im Gewebe eignen sich die Hämatoxilin-Eosinund Grocott-Färbung zur morphologischen Differenzierung unterschiedlicher Zygomyzeten. Die pulmonale Mucormykose zeigt sowohl klinisch als auch histomorphologisch viele Ähnlichkeiten mit der Aspergilluspneumonie. Das charakteristische pathologische Bild ist die extensive Pilzinvasion des Lungenparenchyms und der Gefäße, aus der sich hämorrhagische Infarzierungsherde ableiten. Auffallend sind die häufig lediglich diskret ausfallenden 


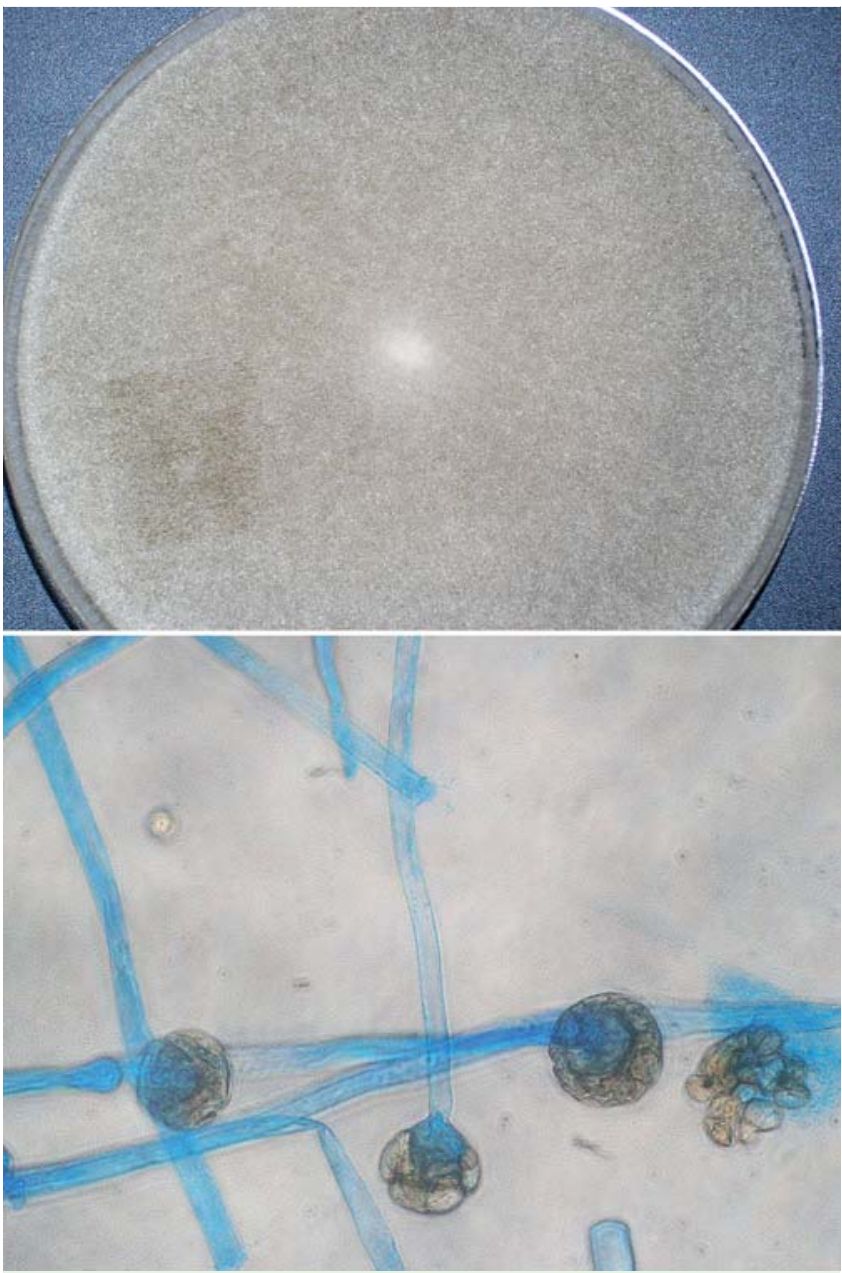

Abb. 3 Kultur und Mikroskopie von Mucor sp. Makroskopisch imponieren die Kolonien von Mucor häufig weiß/wollig, ehe sie im Laufe der Sporulation einen mehr grauen bis braunen Farbton annehmen. Mikroskopische Charakteristika sind die unseptierten Hyphen und die Anordnung der Sporangien.

Entzündungsinfiltrate [56]. Die Erreger können morphologisch von Aspergillus durch ihren größeren Durchmesser von 10$15 \mu \mathrm{m}$ und die fehlende Hyphenseptierung unterschieden werden. Sie sind häufig fragmentiert und zeigen irreguläre, dichotome Aufzweigungen zwischen 45 und 90 Grad. Obwohl sie sich in der HE- und PAS-Färbung basophil darstellen, werden mit einer Versilberungstechnik die besten Resultate erzielt.

\section{Hefepilze}

Candidose

Epidemiologie: Candida sp. gehören zur normalen Flora des oberen Respirationstraktes. Neben C. albicans finden sich C. glabrata, C. tropicalis und C. krusei als Kolonisatoren des oberen Respirationstrakts. Der mikrobielle Nachweis von Candida bei beatmeten oder immunsupprimierten Patienten ist alleine kein wegweisender Befund in der Diagnostik einer invasiven Candidose der Lunge. Die Sicherung der Diagnose gelingt meist nur bei histopathologischem Nachweis von Hyphen und Pseudohyphen.

Klinik: Bei hämato-onkologischen Hochrisikopatienten sind mukokutane Candidosen (z.B. Soorösophagitis) und disseminierte Candidosen ein häufiges Problem. Zu einer pulmonalen Candidose kommt es im Rahmen einer Fungämie. Hingegen ist die primär bronchogene invasive Candidapneumonie eine Rarität. Der kul- turelle Candidanachweis aus respiratorischen Sekreten ist häufig (Kolonisation) und als alleiniger Befund nicht behandlungswürdig. Es sollte gezielt nach Hinweisen für eine systemische Infektion gesucht werden. Wegweisend können eine positive Blutkultur, eine Endophthalmitis, eine Candidurie und septische Herde in anderen Organen (insbesondere hepatolienale Candidose) sein. Zur Klassifikation der sicheren, wahrscheinlichen und möglichen Candidainfektion bei hämatologischen Risikopatienten siehe $\bullet$ Tab. 2.

Anhand großer klinischer Studien ist belegt, dass eine Assoziation zwischen einer Candidakolonisation des Respirationstrakts und der Entstehung nosokomialer bakterieller Pneumonien, insbesondere als Beatmungspneumonie mit Pseudomonas sp., besteht [57]. Ob die Kolonisation hierbei als Marker für die Schwere der Erkrankung oder als Wegbereiter für die bakterielle Infektion zu deuten ist, bleibt unklar.

Bildgebung: Wie bei der IPA können das Halo-Zeichen, eine Kavernenbildung und Milchglasinfiltrate Marker einer Infektion sein. Mithilfe dieser Zeichen kann jedoch nicht zwischen den einzelnen Pilzinfektionen diskriminiert werden [58]. Tendenziell finden sich Knötchenbildung und Infiltrate häufiger bei der IPA.

Mikrobiologie: Da viele Patienten eine Candidabesiedlung aufweisen, ist der kulturelle Nachweis von Candida in respiratorischen Sekreten wenig hilfreich. Hingegen ist der Nachweis von Candida sp. im Gewebe oder primär sterilen Materialien (Pleura, Blut) bei Hochrisikopatienten wegweisend.

Die Sensitivität des Serum-Antigentests zum Nachweis von 1,3$\beta$-D-Glukan liegt bei Hochrisikopatienten bei ca. $80 \%$ mit, je nach Patientenkollektiv, sehr variabler Testspezifität [59]. Ein positives Testergebnis kann auch bei Infektionen mit Aspergillus sp. und Zygomyzeten, nicht jedoch bei einer Cryptokokkose vorkommen [60]. Bei einem positiven Vorhersagewert von nur 59\% für eine invasive Candidose wird der $\beta$-D-Glukan-Test ebenso wie die Candida-Antikörper-Bestimmung nicht für die klinische Routinediagnostik empfohlen [61]. Bei Patienten mit nachgewiesener Candidämie kann die $\beta$-D-Glukan-Titerbestimmung zur Verlaufskontrolle herangezogen werden.

Histopathologie: Die hämatogene Aussaat verursacht miliare, disseminierte, zwei bis vier Millimeter große Knötchen innerhalb des Lungenparenchyms [62,63]. Im nekrotischen Zentrum gelegene Pilzhyphen werden im Randbereich von einem granulozytären Infiltrat (in Abhängigkeit vom Immunstatus des Patienten) umgeben. Die Knötchen haben eine Assoziation zu den Gefäßen, wobei eine Pilzinvasion mit konsekutiver Thrombosierung und Infarzierung des Lungenparenchyms, wie bei einer Aspergillose, nicht beobachtet wird. Anhäufungen von Pseudohyphen, die elongierten Blastosporen entsprechen, und keimende Hefen sind in den Nekrosezonen nachweisbar. Diese sind bereits in der HE-Färbung sichtbar, kommen jedoch wesentlich besser in der PAS- und Gomori-Methenamin-Silber (GMS)-Färbung zur Darstellung.

\section{Kryptokokkose}

Epidemiologie: Infektionen mit dem Hefepilz Cryptococcus neoformans waren bis in die 50er-Jahre eine Rarität. Insbesondere durch die HIV-Epidemie und die Organtransplantationen ist es zu einem deutlichen Anstieg der Infektionen gekommen. Der Erreger wird weltweit im Erdreich und in Vogelkot nachgewiesen.

Klinik: Die Lunge ist die Eintrittspforte für invasive Kryptokokken-Erkrankungen. Die Beteiligung der Lunge reicht von asymptomatischer Besiedlung (insbesondere bei Patienten mit chronischer Lungenerkrankung) bis zu der Entstehung eines ARDS [64]. 
Tab. 4 Mikrobiologische Diagnostik von pulmonalen Mykosen.

Gewinnung von Untersuchungsmaterial

Lagerung $<2 \mathrm{~h}$ bei Raumtemperatur oder $<24 \mathrm{~h}$ bei $4{ }^{\circ} \mathrm{C}$

erforderliche Menge: $\mathrm{BAL}>10 \mathrm{ml}$, Biopsien >0,5 g, induziertes Sputum $>3 \mathrm{ml}$

bevorzugt Material aus den tiefen Atemwegen

bei V.a. endemische Pilze unbedingt vorher das zuständige Labor informieren

bei V. a. endemische Pilze auch Morgensputum und Tracheal-/Bronchialsekrete möglich

semiquantitative bzw. quantitative Auswertung, insbesondere bei Candida spp.

bei Immunsupprimierten und V.a. Disseminierung Anlage weiterer

Materialien (Urin, Blut)

\section{Kultur und Differenzierung}

Wachstum der meisten Pilze innerhalb von 1 - 2 Tagen (ggf. Anlage auf Spezialmedien)

Ausnahme: keine Anzucht von Pneumocystis jiroveci!

Verdachtsdiagnose (z. B. Kryptokokken) unbedingt dem Labor mitteilen, da zusätzliche Untersuchungs- und Kulturbedingungen (Tuschepräparat, $10 \%$ ige $\mathrm{KOH}$-Lösung, Temperatur, u. a.) und längere Bebrütungszeiten notwendig

Differenzierung mikroskopisch-morphologisch, biochemisch und molekular

\section{Bewertung}

nur in Zusammenhang mit klinischen Angaben möglich (z. B. Immunsuppression)

bei Candida sp. nur bei eindeutiger Klinik und hoher Keimzahl (>10 $70^{7} \mathrm{KBE}$ ) aussagekräftig

der Nachweis von endemischen Pilzen, Kryptokokken und Pneumocysten gilt bei bislang nicht therapierten Patienten unabhängig von der Keimzahl oder des Immunstatus des Patienten als klinisch signifikant Speziallabors für die Diagnostik von Pilzen

Nationales Referenzzentrum für Systemische Mykosen. Institut für Medizinische Mikrobiologie der Universitätskliniken Göttingen, Kreuzbergring 57, 37075 Göttingen. www.nrz-mykosen.de/ Konsiliarlaboratorium für Erreger außereuropäischer Systemmykosen. Robert Koch-Institut, Mykologie, Nordufer 20, 13353 Berlin. www.rki.de/

Eine Prädisposition zu Kryptokokken-Infektionen findet sich bei HIV-Patienten, Patienten mit lymphoproliferativer Erkrankung, Organtransplantation, Sarkoidose und Glukokortikoid-Therapie. Die Erkrankung manifestiert sich zumeist in der Lunge und dem ZNS. HIV-Patienten weisen meist primär einen ZNS-Befall mit Meningoenzephalitis auf.

Bildgebung: Radiologisch finden sich lobuläre, interstitielle, noduläre (einzeln oder multiple), miliare und cavitäre Verlaufsformen mit Lymphadenopathie und Pleuraerguss.

Mikrobiologie: Der mikroskopische Direktnachweis von C. neoformans gelingt, insbesondere aus primär sterilem Material, mithilfe der Tuschefärbung. Nur bei Kapsel-defizienten Erregern fehlt das charakteristische Halo-Zeichen. Der kulturelle Nachweis gelingt meist schon nach 3-5 Tagen, kann jedoch bis zu 3 Wochen in Anspruch nehmen. Asymptomatische pulmonale Besiedlungen sind in der Literatur beschrieben. Zum Beweis der invasiven Infektion (sowohl pulmonal als auch zerebral) werden LatexAgglutinationstests zum Nachweis eines Kryptokokken-Polysaccharid-Antigens in Blut und/oder Liquor durchgeführt. Respiratorische Materialien zum Nachweis von Kryptokokken-Antigen sind zum jetzigen Zeitpunkt nicht ausreichend validiert.

Histopathologie: Es findet sich ein weites Spektrum histologischer Entzündungsformen, von fehlender zellulärer Reaktion bis hin zu nekrotisierenden Granulomen [65-67]. Bei immunkom-

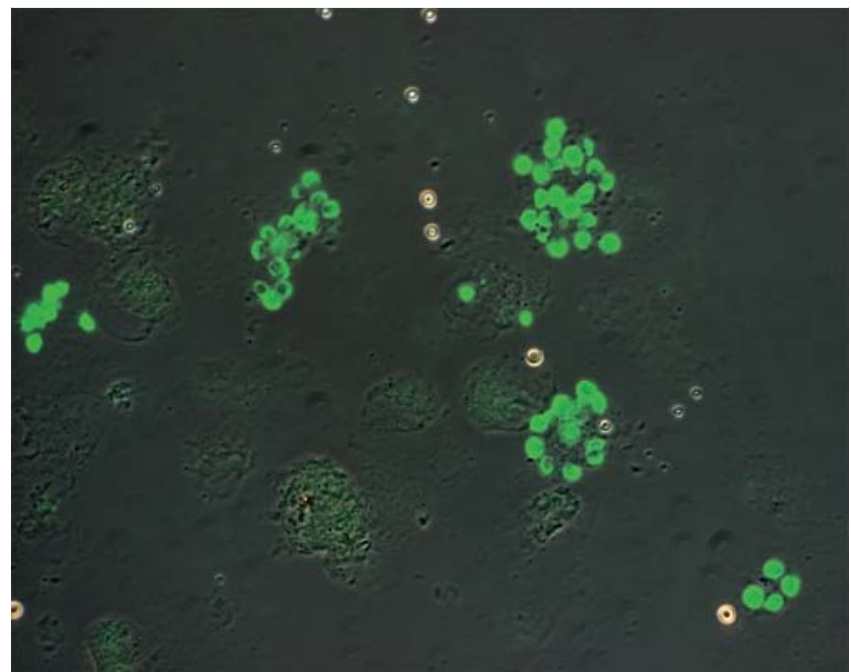

Abb. 4 Nachweis von Pneumocystis jirovecii in BAL- Flüssigkeit eines immunsupprimierten Patienten mit schwerer Dyspnoe. ImmunofluoreszenzFärbung mit FITC-markiertem Antikörper (630 × Vergrößerung).

petenten Patienten kommen nekrotisierende und nicht nekrotisierende Granulome vor. Im fortgeschrittenen Stadium sind mehrkernige Riesenzellen charakteristisch, die sich locker eingestreut mit einer chronischen Entzündungsreaktion und Fibrose vergesellschaften. In der PAS-Färbung lassen sich die bekapselten Erreger aufgrund ihrer Morphologie zumeist gut von anderen Pilzen abgrenzen. Kryptokokken treten als blass blaue, runde Hefen von 2 bis $15 \mu \mathrm{m}$ Durchmesser in der HE-Färbung in Erscheinung und sind häufig fragmentiert. Die Hefen sind durch einen artifiziellen, ungefärbten Retraktionssaum vom Zelldetritus der Nekrose abgesetzt.

Pneumocystose

Epidemiologie: Neben HIV-Patienten mit fortgeschrittenem Im-

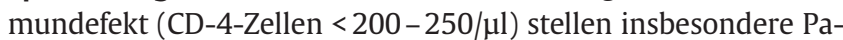
tienten nach Transplantationen und Patienten mit Systemerkrankungen unter kombinierter Immunsuppression eine wichtige Risikogruppe für Infektionen mit Pneumocystis jiroveci (früher Pneumocystis carinii [68]) dar. Eine Kolonisation der Atemwege ist beschrieben [69]. Anders als früher vermutet, ist als Erkrankungsursache eine Neuinfektion wahrscheinlicher als die Reaktivierung [68]. Als Reservoire kommen asymptomatische, kolonisierte HIV-Patienten, manifest an einer Pneumocystis jiroveciPneumonie (PCP) erkrankte Personen und HIV-negative Patienten unter Steroidtherapie infrage [69]. In diesem Zusammenhang wurde eine Assoziation zwischen Pneumocystis-Kolonisation und Schwere der Obstruktion bei COPD-Patienten beschrieben $[70,71]$.

Klinik: Die Patienten klagen über trockenen Husten und Belastungsdyspnoe bei unauffälligem Auskultationsbefund. Fieber, interstitielle Lungeninfiltrate und eine erhöhte Serum-LDH sind Zeichen eines fortgeschrittenen Krankheitsstadiums. In der Lungenfunktion zeigt sich frühzeitig eine respiratorische Partialinsuffizienz mit Diffusionsstörung.

Bildgebung: Erste Röntgenuntersuchungen können unauffällig sein, während in der CT schon früh beidseitig milchglasartige Verschattungen von landkartenartiger Umgrenzung mit Aussparung der subpleuralen Areale sichtbar werden. Fokale Infiltrate und fibroseähnliche Veränderungen kommen vor. 
Mikrobiologie: Bei Verdacht auf PcP ist primär die Durchführung einer Bronchoskopie mit BAL (Trefferquote 85-100\%) sinnvoll: Kontrollierte Untersuchungen im Vergleich zu einer Sputumuntersuchung fehlen jedoch. Die transbronchiale Biopsie (TBB) mit ihrem höheren Komplikationsrisiko hat bei Verdacht auf PcP initial keine Vorteile [72]. Hingegen lässt sich bei Patienten unter Chemoprophylaxe sowie bei negativem Ausfall der Erstdiagnostik die Sensitivität durch eine Mehrlappenlavage (insbesondere im Oberlappen) und eine TBB steigern [73].

Bei schwerer PcP lassen sich Zysten des Erregers bereits morphologisch in Giemsa-gefärbten Ausstrichen der BAL nachweisen. Bei geringer Vergrößerung stellen sich große, runde bis ovaläre, bläuliche Erregeransammlungen dar. Bei höherer Vergrößerung sind diese typischerweise körnig, schaumig oder wabenartig strukturiert. Gut abgrenzbare Zystenwände umschließen basophile punktförmige Strukturen, die den Kernen von Sporozoiten entsprechen. Goldstandard ist weiterhin der Direktnachweis von Pneumocysten im Immunofluoreszenztest (Sensitivität 74-91\%, Spezifität 94-99\%) [74] ( Abb.4). Gesichert werden kann die Diagnose durch die Grocott-Färbung. Kulturelle Anzuchtverfahren für Pneumocysten sind nicht routinemäßig verfügbar. Antikörper eignen sich wegen der schlechten Spezifität (bis zu 90\% der Bevölkerung haben Pneumocystis-Antikörper) nicht zur Diagnostik einer akuten Infektion [74,75]. S-adenosylmethionine steigt während der PcP Therapie an, ist aber noch nicht ausreichend als Instrument zur Therapiekontrolle untersucht [76].

Die PCR zum Nachweis einer PcP muss kritisch bewertet werden. Es handelt sich bei allen beschriebenen Methoden um „in-house Verfahren“. Die Sensitivität aus BAL liegt bei über 90\% [74,77]. Auch wenn eine Labor-zertifizierte PCR bisher nicht existiert, kann bei entsprechender Laborqualität (z.B. Positivkontrollen aus mikroskopisch positiven Patientenproben) eine negative PCR aus BAL beim Ausschluss einer signifikanten Infektion hilfreich sein. Bei positiver PCR ist eine Färbung des Ausstriches zu fordern. Die Real-Time-PCR kann durch DNA-Quantifizierung möglicherweise die Besiedlung von einer Infektion unterscheiden [78], klinische Daten hierzu fehlen. In Ausbruchssituationen kann eine genomische Typisierung weiterhelfen [79]. Vielversprechend sind Ansätze zur Vitalitätsbestimmung durch RNAAnalysen und genomische Typisierungen zur epidemiologischen Charakterisierung von P. jiroveci in Ausbruchssituation [79].

Histopathologie: Histologisch lässt sich innerhalb der Alveolen schaumiges Material nachweisen, häufig assoziiert mit einer interstitiellen Pneumonie [80,81]. Ein diffuser Alveolarschaden mit hyalinen Membranen bei Fibrinauflagerungen der Alveolarwände ist ein typisches Erscheinungsbild der Erkrankung [82 84]. Seltener findet sich eine granulomatöse Entzündung oder fokale Verkalkungen. Bei schweren Verläufen kann es zu Parenchymnekrosen, assoziiert mit einer nekrotisierenden Vaskulitis, und zu Einschmelzungen kommen [85].

\section{Schlussfolgerungen}

$\nabla$

Obwohl sich in den vergangenen Jahren die therapeutischen Optionen zur Therapie invasiver Mykosen durch Weiterentwicklung der Azole und Antimykotika mit neuen Angriffspunkten deutlich verbessert haben, werden weiterhin meist schwere und häufig letal verlaufende Infektionen beobachtet. Im klinischen Alltag bereitet insbesondere die frühe Diagnosestellung einer invasiven Mykose, die durch einen rechtzeitigen Therapiebeginn zur signifikanten Reduktion von Morbidität und Mortalität der
Patienten führt, Schwierigkeiten. In der Diagnostik von Pilzinfektionen der Lunge gilt es zunächst endemische von primär opportunistischen Mykosen anhand der Anamnese, bestehender Vorerkrankungen und Therapien zu differenzieren. Weder klinisch noch radiologisch lassen sich Pilzinfektionen der Lunge klar gegenüber bakteriellen oder nicht infektiösen Lungenentzündungen abgrenzen. Primäre Lungeninfektionen mit Candida sp. oder Aspergillus sp. sind bei immungesunden Personen eine absolute Rarität. Der kulturelle Nachweis von Candida sp. und Aspergillus sp. aus respiratorischen Sekreten dieser Personen reflektiert zumeist eine Besiedlung der Atemwege, die Diagnosesicherung einer invasiven Infektion sollte deshalb histopathologisch im Gewebe oder durch den Nachweis in primär sterilen Materialien (Blutkultur, Pleurapunktat) erfolgen. Serologische Verfahren zum Nachweis spezifischer Antigenbestandteile bzw. Antikörper sind bei Hochrisiko-Patienten für eine invasive Mykose (Neutropenie, Immunsuppression, u.a.) als Verlaufs- und Therapiekontrolle einer kulturell bzw. histopathologisch gesicherten Mykose sinnvoll. Bei niedriger Spezifität sollten diese Tests jedoch nicht zum Screening auf invasive Pilzinfektionen eingesetzt werden. Aufgrund der limitierten diagnostischen Möglichkeiten insbesondere in der Frühphase der Infektion und der damit einhergehenden hohen Mortalität stellen invasive Mykosen der Lunge weiterhin ein schwerwiegendes klinisches Problem dar.

\section{Interessenkonflikte}

$\nabla$

Die Autoren geben an, dass kein Interessenkonflikt besteht.

\section{Literatur}

1 Kar PM, Montalvo FA, Salazar DM et al. Blastomycosis: case report investigating a persistent pulmonary lesion in an immunocompromised patient 1. J Ky Med Assoc 2009; 107: 259-263

2 Dweik M, Baethge BA, Duarte AG. Coccidioidomycosis pneumonia in a nonendemic area associated with infliximab. South Med J 2007; 100: $517-518$

3 Heussel CP, Kauczor HU, Heussel G et al. Early detection of pneumonia in febrile neutropenic patients: use of thin-section CT. AJR Am J Roentgenol 1997; 169: $1347-1353$

4 Cazzadori A, Di Perri G, Todeschini G et al. Transbronchial biopsy in the diagnosis of pulmonary infiltrates in immunocompromised patients. Chest 1995; 107: $101-106$

5 Wong PW, Stefanec T, Brown K et al. Role of fine-needle aspirates of focal lung lesions in patients with hematologic malignancies. Chest 2002; 121: $527-532$

6 White DA, Wong PW, Downey R. The utility of open lung biopsy in patients with hematologic malignancies. Am J Respir Crit Care Med 2000; 161: $723-729$

7 Klein BS, Vergeront JM, Di Salvo AF et al. Two outbreaks of blastomycosis along rivers in Wisconsin. Isolation of Blastomyces dermatitidis from riverbank soil and evidence of its transmission along waterways. Am Rev Respir Dis 1987; 136: 1333-1338

8 Vaaler AK, Bradsher RW, Davies SF. Evidence of subclinical blastomycosis in forestry workers in northern Minnesota and northern Wisconsin. Am J Med 1990; 89: 470-476

9 Chapman SW, Lin AC, Hendricks KA et al. Endemic blastomycosis in Mississippi: epidemiological and clinical studies. Semin Respir Infect 1997; $12: 219-228$

10 Meyer KC, McManus EJ, Maki DG. Overwhelming pulmonary blastomycosis associated with the adult respiratory distress syndrome. $\mathrm{N}$ Engl J Med 1993; 329: 1231 - 1236

11 Ehni W. Endogenous reactivation in blastomycosis. Am J Med 1989; 86: $831-832$

12 Martynowicz MA, Prakash UB. Pulmonary blastomycosis: an appraisal of diagnostic techniques. Chest 2002; 121: 768-773 
13 Lemos LB, Guo M, Baliga M. Blastomycosis: organ involvement and etiologic diagnosis. A review of 123 patients from Mississippi. Ann Diagn Pathol 2000; 4: 391 - 406

14 Sarosi GA, Davies SF. Blastomycosis. Am Rev Respir Dis 1979; 120: 911 938

15 Vanek J, Schwarz J, Hakim S. North American blastomycosis: a study of ten cases. Am J Clin Pathol 1970; 54: 384-400

16 Sudeck $H$. Pulmonary histoplasmosis. A rare import and a chameleon. Der Pneumologe 12-1-2007; 4: 388-399

17 Wheat J, Sarosi G, McKinsey D et al. Practice guidelines for the management of patients with histoplasmosis. Infectious Diseases Society of America. Clin Infect Dis 2000; 30: 688-695

18 Cloud JL, Bauman SK, Pelfrey JM et al. Biased report on the IMMY ALPHA Histoplasma antigen enzyme immunoassay for diagnosis of histoplasmosis. Clin Vaccine Immunol 2007; 14: 1389 - 1390

19 Goodwin RA Jr, Shapiro JL, Thurman GH et al. Disseminated histoplasmosis: clinical and pathologic correlations. Medicine (Baltimore) 1980; 59: $1-33$

20 Klatt EC, Cosgrove M, Meyer PR. Rapid diagnosis of disseminated histoplasmosis in tissues. Arch Pathol Lab Med 1986; 110: 1173-1175

21 Reynolds RJ III, Penn RL, Grafton WD et al. Tissue morphology of Histoplasma capsulatum in acute histoplasmosis. Am Rev Respir Dis 1984; 130: $317-320$

22 Ampel NM, Mosley DG, England B et al. Coccidioidomycosis in Arizona: increase in incidence from 1990 to 1995. Clin Infect Dis 1998; 27: $1528-1530$

23 Miller MB, Hendren R, Gilligan PH. Posttransplantation disseminated coccidioidomycosis acquired from donor lungs. J Clin Microbiol 2004; 42: $2347-2349$

24 Crum NF, Ballon-Landa G. Coccidioidomycosis in pregnancy: case report and review of the literature. Am J Med 2006; 119: 993 -997

25 Galgiani JN, Ampel NM, Catanzaro A et al. Practice guideline for the treatment of coccidioidomycosis. Infectious Diseases Society of America. Clin Infect Dis 2000; 30: 658-661

26 Binnicker MJ, Buckwalter SP, Eisberner JJ et al. Detection of Coccidioides species in clinical specimens by real-time PCR. J Clin Microbiol 2007; 45: $173-178$

27 Ulbright TM, Katzenstein AL. Solitary necrotizing granulomas of the lung: differentiating features and etiology. Am J Surg Pathol 1980; 4: $13-28$

28 Deppisch LM, Donowho EM. Pulmonary coccidioidomycosis. Am J Clin Pathol 1972; 58: 489-500

29 Echols RM, Palmer DL, Long GW. Tissue eosinophilia in human coccidioidomycosis. Rev Infect Dis 1982; 4: 656- 664

30 Lombard CM, Tazelaar HD, Krasne DL. Pulmonary eosinophilia in coccidioidal infections. Chest 1987; 91: 734-736

31 Loo VG, Bertrand C, Dixon C et al. Control of construction-associated nosocomial aspergillosis in an antiquated hematology unit. Infect Control Hosp Epidemiol 1996; 17: 360 - 364

32 Kistemann T, Huneburg H, Exner $M$ et al. Role of increased environmental Aspergillus exposure for patients with chronic obstructive pulmonary disease (COPD) treated with corticosteroids in an intensive care unit. Int J Hyg Environ Health 2002; 204: 347 - 351

33 Ascioglu S, Rex JH, de Pauer B et al. Defining opportunistic invasive fungal infections in immunocompromised patients with cancer and hematopoietic stem cell transplants: an international consensus. Clin Infect Dis 2002; 34: 7-14

34 Caillot D, Couaillier JF, Bernard A et al. Increasing volume and changing characteristics of invasive pulmonary aspergillosis on sequential thoracic computed tomography scans in patients with neutropenia. J Clin Oncol 2001; 19: 253-259

35 Greene RE, Schlamm HT, Oestmann JW et al. Imaging findings in acute invasive pulmonary aspergillosis: clinical significance of the halo sign. Clin Infect Dis 2007; 44: 373-379

36 Kahn FW, Jones JM, England DM. The role of bronchoalveolar lavage in the diagnosis of invasive pulmonary aspergillosis. Am J Clin Pathol $1986 ; 86: 518-523$

37 Glasmacher A, Marklein G, Just-Nubling G et al. Diagnosis of invasive mycoses in neutropenic patients with systemic hematologic diseases. Dtsch Med Wochenschr 1998; 123: 157-160

38 Horvath JA, Dummer S. The use of respiratory-tract cultures in the diagnosis of invasive pulmonary aspergillosis. Am J Med 1996; 100: $171-178$

39 Spiess B, Buchheidt D, Baust C et al. Development of a LightCycler PCR assay for detection and quantification of Aspergillus fumigatus DNA in clinical samples from neutropenic patients. J Clin Microbiol 2003; 41: $1811-1818$

40 Aubry A, Porcher R, Bottero J et al. Occurrence and kinetics of false-positive Aspergillus galactomannan test results following treatment with beta-lactam antibiotics in patients with hematological disorders. J Clin Microbiol 2006; 44: $389-394$

41 Cummings JR, Jamison GR, Boudreaux JW et al. Cross-reactivity of nonAspergillus fungal species in the Aspergillus galactomannan enzyme immunoassay. Diagn Microbiol Infect Dis 2007; 59: 113-115

42 Clancy CJ, Jaber RA, Leather HL et al. Bronchoalveolar lavage galactomannan in diagnosis of invasive pulmonary aspergillosis among solid-organ transplant recipients. J Clin Microbiol 2007; 45: 1759-1765

43 Maertens J, Maertens $V$, Theunissen Ket al. Bronchoalveolar lavage fluid galactomannan for the diagnosis of invasive pulmonary aspergillosis in patients with hematologic diseases. Clin Infect Dis 2009; 49: 1688 1693

44 Meersseman W, Lagrou K, Maertens J et al. Galactomannan in bronchoalveolar lavage fluid: a tool for diagnosing aspergillosis in intensive care unit patients. Am J Respir Crit Care Med 2008; 177: 27 - 34

45 Rantakokko-Jalava K, Laaksonen S, Issakainen J et al. Semiquantitative detection by real-time PCR of Aspergillus fumigatus in bronchoalveolar lavage fluids and tissue biopsy specimens from patients with invasive aspergillosis. J Clin Microbiol 2003; 41: 4304-4311

46 Khot PD, Ko DL, Hackman RC et al. Development and optimization of quantitative PCR for the diagnosis of invasive aspergillosis with bronchoalveolar lavage fluid. BMC Infect Dis 2008; 8: 73

47 Fraser RS. Pulmonary aspergillosis: pathologic and pathogenetic features. Pathol Annu 1993; 28 Pt 1: $231-277$

48 Young RC, Bennett JE, Vogel CL et al. Aspergillosis. The spectrum of the disease in 98 patients. Medicine (Baltimore) 1970; 49: 147-173

49 Gefter WB. The spectrum of pulmonary aspergillosis. J Thorac Imaging 1992; 7: $56-74$

50 Ghio AJ, Peterseim DS, Roggli VL et al. Pulmonary oxalate deposition associated with Aspergillus niger infection. An oxidant hypothesis of toxicity. Am Rev Respir Dis 1992; 145: 1499-1502

51 Kimmerling EA, Fedrick JA, Tenholder MF. Invasive Aspergillus niger with fatal pulmonary oxalosis in chronic obstructive pulmonary disease. Chest 1992; 101: $870-872$

52 Rickerts V, Mousset S, Lambrecht E et al. Comparison of histopathological analysis, culture, and polymerase chain reaction assays to detect invasive mold infections from biopsy specimens. Clin Infect Dis 2007; 44: $1078-1083$

53 Chamilos G, Marom EM, Lewis RE et al. Predictors of pulmonary zygomycosis versus invasive pulmonary aspergillosis in patients with cancer. Clin Infect Dis 2005; 41: 60-66

54 Roden MM, Zaoutis TE, Buchanan WL et al. Epidemiology and outcome of zygomycosis: a review of 929 reported cases. Clin Infect Dis 2005; 41: $634-653$

55 Torres-Narbona M, Guinea J, Martinez-Alarcon J et al. Impact of zygomycosis on microbiology workload: a survey study in Spain. J Clin Microbiol 2007; 45: 2051 - 2053

56 Meyer RD, Rosen P, Armstrong D. Phycomycosis complicating leukemia and lymphoma. Ann Intern Med 1972; 77: 871 - 879

57 Azoulay E, Timsit JF, Tafflet $M$ et al. Candida colonization of the respiratory tract and subsequent pseudomonas ventilator-associated pneumonia. Chest 2006; 129: 110 - 117

58 Althoff SC, Muller NL, Marchiori E et al. Pulmonary invasive aspergillosis and candidiasis in immunocompromised patients: a comparative study of the high-resolution CT findings. J Thorac Imaging 2006; 21: 184 189

59 Stevens DA. Diagnosis of fungal infections: current status. J Antimicrob Chemother 2002; 49 Suppl 1: 11 - 19

60 Miyazaki T, Kohno S, Mitsutake K et al. Plasma (1 $\rightarrow 3$ )-beta-D-glucan and fungal antigenemia in patients with candidemia, aspergillosis, and cryptococcosis. J Clin Microbiol 1995; 33: 3115 - 3118

61 Obayashi T, Yoshida M, Mori $T$ et al. Plasma ( $\rightarrow 3$ )-beta-D-glucan measurement in diagnosis of invasive deep mycosis and fungal febrile episodes. Lancet 7-1-1995; 345: 17-20

62 Masur H, Rosen PP, Armstrong D. Pulmonary disease caused by Candida species. Am J Med 1977; 63: 914-925

63 Rose H, Sheth N. Pulmonary candidiasis. A clinical and pathological correlation. Arch Int Med 1978; 138: 964

64 Henson DJ, Hill AR. Cryptococcal pneumonia: a fulminant presentation. Am J Med Sci 1984; 288: 221 - 222 
65 Baker $R D$. The primary pulmonary lymph node complex of crytptococcosis. Am J Clin Pathol 1976; 65: 83-92

66 Farmer SG, Komorowski RA. Histologic response to capsule-deficient Cryptococcus neoformans. Arch Pathol 1973; 96: 383-387

67 Kahn FW, England DM, Jones JM. Solitary pulmonary nodule due to Cryptococcus neoformans and Mycobacterium tuberculosis. Am J Med 1985; 78: 677-681

68 Stringer JR, Beard CB, Miller RF et al. A new name (Pneumocystis jiroveci) for Pneumocystis from humans. Emerg Infect Dis 2002; 8: 891 - 896

69 Wakefield AE, Lindley AR, Ambrose HE et al. Limited asymptomatic carriage of Pneumocystis jiroveci in human immunodeficiency virus-infected patients. J Infect Dis 2003; 187: 901 - 908

70 Calderon EJ, Rivero L, Respaldiza $\mathrm{N}$ et al. Systemic inflammation in patients with chronic obstructive pulmonary disease who are colonized with Pneumocystis jiroveci. Clin Infect Dis 2007; 45: e17 - e19

71 Morris A, Sciurba FC, Lebedeva IP et al. Association of chronic obstructive pulmonary disease severity and Pneumocystis colonization. Am J Respir Crit Care Med 15-8-2004; 170: 408-413

72 Baughman RP, Dohn MN, Frame PT. The continuing utility of bronchoalveolar lavage to diagnose opportunistic infection in AIDS patients. Am J Med 1994; 97: 515-522

73 Cadranel J, Gillet-Juvin K, Antoine M et al. Site-directed bronchoalveolar lavage and transbronchial biopsy in HIV-infected patients with pneumonia. Am J Respir Crit Care Med 1995; 152: 1103-1106

74 Riebold D, Löbermann $M$, Reisinger EC. Diagnostic features and resistance testing of Pneumocystis jirovecii. J Lab Med 2008; 32: 35 - 39

75 Morris A, Netravali M, Kling HM et al. Relationship of pneumocystis antibody response to severity of chronic obstructive pulmonary disease. Clin Infect Dis 2008; 47: e64-e68

76 Skelly MJ, Holzman RS, Merali S. S-adenosylmethionine levels in the diagnosis of Pneumocystis carinii pneumonia in patients with HIV infection. Clin Infect Dis 2008; 46: 467-471

77 Gupta R, Mirdha BR, Guleria R et al. Diagnostic significance of nested polymerase chain reaction for sensitive detection of Pneumocystis jirovecii in respiratory clinical specimens. Diagn Microbiol Infect Dis 2009; 64: $381-388$

78 Larsen HH, Kovacs JA, Stock F et al. Development of a rapid real-time PCR assay for quantitation of Pneumocystis carinii f. sp. carinii. J Clin Microbiol 2002; 40: 2989-2993

79 Huang L, Morris A, Limper AH et al. An Official ATS Workshop Summary: Recent advances and future directions in pneumocystis pneumonia (PCP). Proc Am Thorac Soc 2006; 3: 655-664

80 Luna MA, Cleary KR. Spectrum of pathologic manifestations of Pneumocystis carinii pneumonia in patients with neoplastic diseases. Semin Diagn Pathol 1989; 6: 262-272
81 Travis WD, Pittaluga S, Lipschik GY et al. Atypical pathologic manifestations of Pneumocystis carinii pneumonia in the acquired immune deficiency syndrome. Review of 123 lung biopsies from 76 patients with emphasis on cysts, vascular invasion, vasculitis, and granulomas. Am J Surg Pathol 1990; 14: 615-625

82 Askin FB, Katzenstein AL. Pneumocystis infection masquerading as diffuse alveolar damage: a potential source of diagnostic error. Chest 1981; 79: 420-422

83 Dee P, Winn W, McKee K. Pneumocystis carinii infection of the lung: radiologic and pathologic correlation. AJR Am J Roentgenol 1979; 132: $741-746$

84 Weber WR, Askin FB, Dehner LP. Lung biopsy in Pneumocystis carinii pneumonia: a histopathologic study of typical and atypical features. Am J Clin Pathol 1977; 67: 11 - 19

85 Liu YC, Tomashefski JF Jr, Tomford JW et al. Necrotizing Pneumocystis carinii vasculitis associated with lung necrosis and cavitation in a patient with acquired immunodeficiency syndrome. Arch Pathol Lab Med 1989; 113: 494-497

\section{Bisher erschienene Beiträge dieser Serie}

$\nabla$

1 Strassburg A et al. Infektionsdiagnostik in der Pneumologie. Teil 1. Übersicht und Methoden. Pneumologie 2008; 62: 730-743

2 Rohde G et al. Nachweis von Atemwegsviren - Wie, warum, wann und wo? Pneumologie 2009; 63: 14-22

3 Gillissen A et al. Biomarker bei infektiösen und nicht infektiösen Lungenerkrankungen außer Malignome. Pneumologie 2009; 63: 439-450

$4 \mathrm{Ott} S$ et al. Die Rolle von Viren bei tiefen Atemwegsinfektionen des Erwachsenen. Teil 1: Erreger, Pathogenese und Diagnostik. Pneumologie 2009; 63: 709-717

5 Ott $S$ et al. Die Rolle von Viren bei tiefen Atemwegsinfektionen des Erwachsenen. Teil 2: Akute Bronchitis, exacerbierte COPD, Pneumonie und Influenza. Pneumologie 2010; 64: 18- 27

6 Ott $S$ et al. Die Rolle von Viren bei tiefen Atemwegsinfektionen des Erwachsenen. Teil 3: Therapie und Prävention. Pneumologie 2010; 64: $115-123$

7 Strassburg A et al. Infektionsdiagnostik in der Pneumologie. Teil 2: Nachweis von bakteriellen Mikroorganismen aus dem Tracheobronchialsystem: Infektion oder Kolonisation? Pneumologie 2010; 64: $291-299$

8 Höffken $G$ et al. Aktuelle Konzepte zum mikrobiologischen Nachweis von Atemwegserregern. Pneumologie 2010; 64: 184-193 